\title{
BISM \\ ONLINE \\ The clinical utility of screening of biochemical parameters in elite athletes Analysis of 100 cases
}

Kieran Edward Fallon

Br. J. Sports Med. published online 10 Dec 2007;

doi:10.1136/bjsm.2007.041137

Updated information and services can be found at:

http://bjsm.bmj.com/cgi/content/abstract/bjsm.2007.041137v1

\section{These include:}

Rapid responses You can respond to this article at: http://bjsm.bmj.com/cgi/eletter-submit/bjsm.2007.041137v1

Email alerting service

Receive free email alerts when new articles cite this article - sign up in the box at the top right corner of the article

Notes

Online First contains unedited articles in manuscript form that have been peer reviewed and accepted for publication but have not yet appeared in the paper journal (edited, typeset versions may be posted when available prior to final publication). Online First articles are citable and establish publication priority; they are indexed by PubMed from initial publication. Citations to Online First articles must include the digital object identifier (DOIs) and date of initial publication.

To order reprints of this article go to:

http://journals.bmj.com/cgi/reprintform

To subscribe to British Journal of Sports Medicine go to:

http://journals.bmj.com/subscriptions/ 


\section{The clinical utility of screening of biochemical parameters in elite athletes - Analysis of 100 cases.}

Key words; elite, biochemical, screening

Kieran Edward Fallon

Department of Sports Medicine

Australian Institute of Sport

Keywords: elite, athlete, biochemical, screening 


\section{Abstract}

Objective: To determine the clinical utility of screening for biochemical parameters in elite athletes.

\section{Design: A prospective sequential case series}

Setting: The Department of Sports Medicine at the Australian Institute of Sport

Participants: One hundred elite athletes from eleven sports, 56 males and 44 females, mean age for both groups 19 years, undergoing routine medical screening.

Intervention: Initial and follow-up assessment of the following biochemical parameters in association with clinical assessment; serum iron, ferritin, transferrin, percent transferrin saturation, sodium, potassium, chloride, calcium, magnesium, phosphate, urate, urea and creatinine, total protein, albumin, creatine kinase (CK), lactate dehydrogenase (LDH), aspartate aminotransaminase (AST), alanine aminotransferase (ALT), alkaline phosphatase (ALP), gamma-glutamyl transpeptidase (GGT), total bilirubin, cholesterol and triglycerides (non-fasting) and random glucose (BSL).

Results: Eighteen athletes demonstrated no abnormalities on biochemical screening. One hundred and ninety-four abnormal results were found in 82 athletes. One hundred and fifteen abnormalities were noted in 46 males and 79 in 36 females. In forty three individual tests the results did not return to normal on repeat testing. The most frequently demonstrated abnormalities were increased AST (27\%), increased phosphate (13\%), increased CK (13\%), increased urea (12\%) and increased bilirubin (12\%). Three cases of hypercholesterolaemia and one case of haemochromatosis were identified and one athlete, who was symptomatic, was diagnosed with Epstein-Barr virus infection suspected when abnormal liver function test were noted. The other abnormalities found appeared not to be of clinical significance.

Conclusion: The vast majority of abnormalities found on routine biochemical screening in elite athletes are of no clinical significance. Therefore such testing should, if used only for clinical purposes, be abandoned. When athletes are tested for iron status it would be prudent to include assessment of serum cholesterol in those with a family history of hyperlipidaemia. 


\section{Introduction}

Performance of screening for biochemical parameters and repeated assessment of these is a widespread procedure in elite sports medicine and exercise physiology. A number of recent studies have assessed the clinical utility of screening for iron-related parameters in elite athletes but to date there are no studies of the clinical utility of screening for other biochemical parameters.

A number of authors have suggested that widespread screening should be performed in an effort to produce a set of normal ranges for elite athletes and these reference intervals are becoming available.[1,2,3,4] Others have suggested that screening of some biochemical variables when athletes are in the rested state may be useful as a baseline for biochemical monitoring of training[5] and others suggest that such monitoring may be useful in the prediction of the onset of overtraining.[6] Each of these are worthy goals but as biochemical monitoring is relatively expensive, involves some discomfort and is inconvenient it is important that each of these potential applications is shown to be worthwhile and also that any clinical application of biochemical screening be determined. The aim of this prospective clinical case series is to commence assessment of this last potential application. The uniqueness of this study lies in the fact that biochemical testing was performed in association with clinical consultations and that each abnormality found was followed up with both a clinical consultation and repeat testing.

\section{Methods}

This study was approved by the Ethics Committee of the Australian Institute of Sport. All procedures conformed to the National Health and Medical Research Council guidelines for experimentation with human subjects and all subjects gave their informed written consent before participation.

All 100 elite athletes (56 males and 44 females) presenting at the Sports Science/Sports Medicine Centre at the Australian Institute of Sport for routine medical screening during a period of approximately one year were entered into the study. All of the athletes were in training and involved in some form of training once or twice a day for at least six days of each week. They underwent a standard medical history and examination by a sports physician and at the conclusion of this blood $(12 \mathrm{ml})$ was drawn under aseptic technique from a vein in the cubital fossa. Blood was drawn immediately following the assumption of the recumbent position and was transported immediately to an adjacent haematology laboratory where analysis was performed on the same day.

Due, generally to training demands, the timing of blood collection was not standardised in relation to periods of training and time of day. Therefore parameters potentially affected by training were almost certainly perturbed from true baseline (resting) levels but as elite athletes do not generally stop 
training because of routine blood tests the results represent a real rather than an artificial situation. Diurnal variation, such as occurs for serum iron, was not able to be corrected for but did not appear to be clinically relevant in any of the cases. All athletes whose screening blood tests revealed abnormalities were interviewed for clinical symptoms and repeat blood testing was performed on all but seven of these athletes with the exception of those who had iron depletion. These athletes were, after dietary assessment, commenced on iron supplements to be followed up three months later at the conclusion of their supplementation program.

The following biochemical parameters were measured on an Hitachi 911 analyser (Roche Diagnostics, Indianapolis, USA) using Roche reagents serum iron, ferritin, transferrin, percent transferrin saturation, sodium, potassium, chloride, calcium, magnesium, phosphate, urate, urea and creatinine, total protein, albumin, creatine kinase (CK), lactate dehydrogenase (LDH) , aspartate aminotransanimase (AST), alanine aminotransferase $(A L T)$, alkaline phosphatase (ALP), gamma-glutamyl transpeptidase (GGT), total bilirubin, cholesterol and triglycerides (non-fasting) and random glucose. A full blood count was also performed and, while the results are not the subject of this paper, these were sometimes used to assist in further assessment of the biochemical abnormalities detected.

Reference intervals were those of the haematology and biochemistry laboratory at the Australian Institute of Sport. The intervals were derived from several thousand elite athletes tested over a period of over five years.

\section{RESULTS}

The athletes were recruited from eleven sports. (Table 1). The mean age for both males and females was 19 years (range for each gender,16-27 years).

\begin{tabular}{|l|c|l|}
\hline Sport & Males & Females \\
\hline Rowing & 12 & 11 \\
\hline Football & 21 & \\
\hline Basketball & 6 & 14 \\
\hline Netball & & 13 \\
\hline Boxing & 9 & \\
\hline Athletics & 1 & 3 \\
\hline Swimming & 1 & 2 \\
\hline Volleyball & 3 & \\
\hline AWD athletics & 2 & \\
\hline Archery & 1 & \\
\hline Canoeing & 1 & \\
\hline & AWD (Athletes with a disability) \\
\hline
\end{tabular}

Table 1 Athletes by sport and gender. 
Eighteen athletes demonstrated no abnormalities on biochemical screening (ten males and eight females). One hundred and ninety-four abnormal results were found in 82 athletes. One hundred and fifteen abnormalities were noted in 46 males and 79 in 36 females.

Abnormalities noted more than once are shown in Table 2.

\begin{tabular}{|l|l|l|}
\hline PARAMETER & MALES & FEMALES \\
\hline Increased AST & 18 & 9 \\
\hline Increased Bilirubin & 11 & 1 \\
\hline Increased CK & 11 & 2 \\
\hline Decreased BSL & 11 & \\
\hline Increased Urate & 9 & \\
\hline Increased Phosphate & 9 & 4 \\
\hline Increased Urea & 6 & 6 \\
\hline Increased Iron & 4 & 5 \\
\hline Increased Tf sat. & 4 & \\
\hline Increased LDH & 4 & 1 \\
\hline Increased TG & 4 & \\
\hline Decreased Iron & 3 & 2 \\
\hline Decreased GGT & 3 & \\
\hline Increased Cholesterol & 2 & 1 \\
\hline Decreased transferrin & 2 & 2 \\
\hline Increased ferritin & 2 & \\
\hline Decreased TF sat & & 10 \\
\hline Decreased Ferritin & & 9 \\
\hline Increased BSL & & 5 \\
\hline Increased ALT & & 5 \\
\hline Decreased Sodium & & 3 \\
\hline Decreased Phosphate & & 2 \\
\hline Decreased Protein & & 2 \\
\hline
\end{tabular}

TABLE 2. Abnormalities represented more than once in male athletes $(n=56)$ and female athletes $(n=44)$ 
In forty three individual tests the results did not return to normal on repeat testing. (Table 3)

\begin{tabular}{|c|c|c|c|c|}
\hline PARAMETER & $\mathrm{N}=$ & $\begin{array}{l}\text { RANGE } \\
\text { INITIAL }\end{array}$ & $\begin{array}{l}\text { RANGE } \\
\text { REPEAT }\end{array}$ & $\begin{array}{l}\text { REFERENCE } \\
\text { INTERVAL }\end{array}$ \\
\hline Bilirubin $\uparrow$ & 9 & 19-57 umol/L & 18-43 umol/L & 0-17umol/L \\
\hline AST $\uparrow$ & 6 & 39-74 U/L & $40-100 \mathrm{U} / \mathrm{L}$ & $0-38 \mathrm{U} / \mathrm{L}$ \\
\hline $\mathrm{BSL} \uparrow$ & 2 & $6.2-7.4 \mathrm{mmol} / \mathrm{L}$ & $6.3-6.8 \mathrm{mmol} / \mathrm{L}$ & $4.22-6.11 \mathrm{mmol} / \mathrm{L}$ \\
\hline Phosphate $\uparrow$ & 4 & $\begin{array}{l}1.50-1.86 \\
\mathrm{mmol} / \mathrm{L}\end{array}$ & $\begin{array}{l}1.47-1.60 \\
\mathrm{mmol} / \mathrm{L}\end{array}$ & $0.87-1.45 \mathrm{mmol} / \mathrm{L}$ \\
\hline Cholesterol $\uparrow$ & 3 & $\begin{array}{l}5.53-8.84 \\
\mathrm{mmol} / \mathrm{L}\end{array}$ & $\begin{array}{l}5.32-8.10 \\
\mathrm{mmol} / \mathrm{L}\end{array}$ & $1.3-5.2 \mathrm{mmol} / \mathrm{L}$ \\
\hline BSL $\downarrow$ & 4 & $3.4-4.0 \mathrm{mmol} / \mathrm{L}$ & $2.9-4.0 \mathrm{mmol} / \mathrm{L}$ & $4.22-6.11 \mathrm{mmol} / \mathrm{L}$ \\
\hline Tf sat. $\downarrow$ & 2 & $12-13 \%$ & $9-10 \%$ & $15-50 \%$ \\
\hline GGT个 & 1 & $58 \mathrm{U} / \mathrm{L}$ & $40 \mathrm{U} / \mathrm{L}$ & $11-49 \mathrm{U} / \mathrm{L}$ \\
\hline GGT $\downarrow$ & 1 & $10 \mathrm{U} / \mathrm{L}$ & $9 \mathrm{U} / \mathrm{L}$ & $11-49 \mathrm{U} / \mathrm{L}$ \\
\hline $\mathrm{CK} \uparrow$ & 1 & $1732 \mathrm{U} / \mathrm{L}$ & $3428 \mathrm{U} / \mathrm{L}$ & $0-780 \mathrm{U} / \mathrm{L}$ \\
\hline Triglycerides & 1 & $2.88 \mathrm{mmol} / \mathrm{L}$ & $3.52 \mathrm{mmol} / \mathrm{L}$ & $0.0-2.3 \mathrm{mmol} / \mathrm{L}$ \\
\hline Transferrin $\downarrow$ & 2 & $\begin{array}{l}2.01-2.14 \\
\mathrm{ng} / \mathrm{ml}\end{array}$ & $\begin{array}{l}2.00-2.08 \\
\mathrm{ng} / \mathrm{ml}\end{array}$ & $2.3-4.5 \mathrm{~g} / \mathrm{L}$ \\
\hline Urea $\uparrow$ & 2 & $\begin{array}{l}11.0-11.3 \\
\mathrm{mmol} / \mathrm{L}\end{array}$ & $\begin{array}{l}8.5-9.8 \\
\mathrm{mmol} / \mathrm{L}\end{array}$ & $1.7-8.3 \mathrm{mmol} / \mathrm{L}$ \\
\hline Iron $\uparrow$ & 1 & $63.0 \mathrm{umol} / \mathrm{L}$ & $33.2 \mathrm{umol} / \mathrm{L}$ & 10.6-28.3 umol/L \\
\hline Ferritin $\uparrow$ & 1 & $496 \mathrm{ng} / \mathrm{ml}$ & $471 \mathrm{ng} / \mathrm{ml}$ & $30-300 \mathrm{ng} / \mathrm{ml}$ \\
\hline Tf sat $\uparrow$ & 1 & $69 \%$ & $57 \%$ & $15-50 \%$ \\
\hline Sodium $\downarrow$ & 1 & $134 \mathrm{mmol} / \mathrm{L}$ & $133 \mathrm{mmol} / \mathrm{L}$ & $135-150 \mathrm{mmol} / \mathrm{L}$ \\
\hline Calcium & 1 & $2.57 \mathrm{mmol} / \mathrm{L}$ & $2.44 \mathrm{mmol} / \mathrm{L}$ & $2.15-2.55 \mathrm{mmol} / \mathrm{L}$ \\
\hline
\end{tabular}

Table 3 Individual test results that did not return to normal on repeat testing.

In eleven cases the abnormalities were consistent with clinical entities. Three cases had confirmed hypercholesterolaemia. Four cases in which iron-related parameters were abnormal were explained by concurrent infections. One case of increased serum iron was associated with ingestion of iron supplements and one case of an increase in GGT was associated with alcohol ingestion. One case which demonstrated increases in LDH, AST, ALT and ALP had, on follow-up, an associated lymphocytosis and positive serology for Epstein-Barr virus infection. The patient was asymptomatic. One athlete with a persistent elevation in transferrin saturation and normal serum ferritin was diagnosed with haemochromatosis after testing homozygous for the C282Y mutation.

The ten cases with serum ferritin less than $30 \mathrm{ng} / \mathrm{ml}$ were deemed to be at risk of iron depletion and were placed on supplementation without retesting. 
Seven athletes did not have follow-up blood tests. Several athletes decided not to have further tests when it was suggested that the probable cause was a normal response to training. Two athletes had a GGT level of $10 \mathrm{U} / \mathrm{L}$ (normal range $11-49 \mathrm{U} / \mathrm{L}$ ) in the presence of normal other liver function tests and one athlete moved away.

\section{DISCUSSION}

Screening may be defined as an attempt to detect disease in asymptomatic persons. For screening to be effective three sets of considerations must be assessed - the characteristics of the target population, the diseases targeted for detection and the nature of the tests that are proposed. Tabas and Vanek[7] have suggested that, in relation to the population concerned, the main considerations are; the prevalence of the disease, the accessibility of the population and likely compliance with follow-up diagnostic tests and therapy. In relation to the disease, detection should have a significant effect on the quality or length of life, acceptable methods of treatment should be available and improved outcomes from treatment in the asymptomatic phase should occur. The tests should be sensitive enough to detect the disease in the asymptomatic period, sufficiently specific to provide acceptable predictive value and be acceptable to patients.

In many cases few of these factors are considered before routine biochemical screening is performed on elite athletes and indeed much of the screening performed appears to be for reasons other than detection of disease in the asymptomatic.

The clinical utility of biochemical screening using multiple parameters has often been assessed in the general non-athletic population. Based on a review of seven studies, Cebul and Beck[8] concluded that biochemical profiles are not warranted in asymptomatic persons and that determination of serum glucose, cholesterol and "with modest enthusiasm" serum creatinine, is sufficient. In a more recent study Ruttiman[9] and colleagues reported on screening using 23 biochemical parameters in 493 patients of mean age 41 years. Sixty new diagnoses were made resulting in new management in $5 \%$ of patients. Only $0.2 \%$ of tests led to new management. The four most common new diagnoses were hypercholesterolaemia (52\%), hypertriglyceridaemia (13\%), hyperuricaemia (10\%) and "slight abnormalities of liver enzymes of unknown origin" (7\%). The rate of individuals with abnormal routine tests was $88 \%$. These authors suggested the vast majority of clinically significant abnormalities could have been detected by use of a short test panel comprised of serum cholesterol, glucose and alanine aminotransferase. Based on these studies one could quite reasonably suspect that the clinical utility of biochemical screening in a very fit and generally health population such as one composed exclusively of elite athletes might be somewhat limited.

In this study, the most frequently found abnormality (27 cases) was an increase in AST (range 38-238U/L, 18 cases less than 50U/L). Twelve of these were associated with CK levels greater than $780 \mathrm{U} / \mathrm{L}$ (the upper limit of 
normal for the AIS laboratory), suggesting a skeletal muscle origin, twentyone were associated with other "liver function tests" which were completely normal and six with elevations in ALT. At both the initial and follow-up consultations there were no symptoms or signs to suggest liver disease or excessive alcohol ingestion. All but six returned to normal on repeat testing which was not performed during the resting state. Based on data from a study of 579 club level athletes the upper limit (mean plus 2 standard deviations) of normal might be as high as $55 \mathrm{U} / \mathrm{L}$ and this would restrict the number of abnormal results for this parameter to eight.[10]

Noakes[11], as long ago as 1987 , described earlier papers that indicated that an elevation in AST can occur following activities as varied as walking on a treadmill for five minutes, a boxing competition, swimming, rowing and callisthenics. In military training AST increases of up to sixfold have been demonstrated[12] and very large elevations have been reported following ultramarathon running.[13] It would appear therefore that increases in AST in elite athletes in training, particularly in association with increases in CK, normal other liver function tests and in the absence of clinical symptoms and signs, are of no clinical significance. As ALT has also been demonstrated to increase in relation to exercise an increase in this enzyme associated with a mild increase in AST is almost certainly of little significance.

A number of commonly used medications including some antibiotics, HMG Co-A reductase inhibitors, anti-epileptic drugs and herbal medications can cause elevations in aminotransferases and in the athletic context in particular, the use non-steroidal antiinflammatory drugs should be considered.[14] None of the athletes were using any of these medications at the time of screening. The oral contraceptive pill may infrequently have a similar effect and is also highly relevant in this population.[15]

An increase in serum bilirubin was found in 11 males and one female athlete (range 20-52umol/L). Of this group, eight cases were associated with normal other liver function tests. On review, bilirubin remained elevated in nine cases. Seven of these were associated with normal liver function tests. Of the others, one had an increased AST with an increased CK and the other had an increase in AST and a normal CK and had been previously investigated and had been diagnosed with Gilbert's syndrome. While it was not proven that the bilirubin in these cases was unconjugated, the absence of abnormalities in the other liver function tests and normal full blood counts in all cases suggests that these athletes also have Gilbert's syndrome. The male preponderance is consistent with previous studies but is greater than is generally reported and the incidence of $9 \%$ is also higher than usual. Despite the fact that endurance exercise has been shown not to lead to an increase in bilirubin in athletes with Gilbert's syndrome[16], an increase in this parameter has been demonstrated following a number of forms of exercise[17] and so perhaps it is not surprising that more cases of this condition are identified in those who are habitually active than in the general population. 
An elevation in serum phosphate (range 1.50-1.86 mmol) was found in thirteen cases. None of these cases was associated with hypocalcaemia. Nine returned to normal on repeat testing and of the four who did not the range was $1.47-1.60 \mathrm{mmol} / \mathrm{L}$. The response of serum phosphate to exercise is quite variable across different forms of activity. For instance, Clarkson and colleagues[18]found no change in this parameter after 50 maximal eccentric contractions of the elbow flexors, which induced marked changes in CK, while Nagel et al demonstrated a $73 \%$ increase in runners competing in a $24 \mathrm{hr}$ footrace.[19] There are no reports of negative clinical consequences of changes in serum phosphate in athletes.

An elevation in serum urea was found in twelve cases. None were associated with increases in serum creatinine and urinalysis was normal in each case. Only two case did not return to normal on repeat testing and in these instances the second result was close to the upper limit of normal. Increases in this parameter are very well described following exercise.[18,19] They are thought to reflect increases in production secondary to degradation of amino acids consequent upon muscle cell damage. Other factors relevant to the context of sport such as increases in ingestion of amino acids and dehydration can also lead to increases in serum urea. The type of change demonstrated here, particularly if associated with normal serum creatinine is of no clinical significance in athletes.

Nine subjects demonstrated an elevation in serum urate. All returned to normal on repeat testing. Mean values at rest in elite athletes have previously been assessed with statistically significant reductions found when both cyclists and skiers were compared with controls.[3] In relation to exercise, changes in this parameter are similar to those of urea, with the source of the metabolite again being related to breakdown of amino acids.[18,19]

Abnormalities in blood glucose were found in eleven males (decreases) and five females (increases). Mean values at rest in elite male athletes have previously been assessed with statistically significant reductions found when both cyclists and skiers were compared with controls.[3] Four cases of a decrease and two of an increase did not return to normal on repeat testing. Neither the initial tests nor the follow-ups were associated with symptoms and appear not to be of clinical significance

The three cases of hypercholesterolaemia which were revealed represent three of the four test results that were of clinical significance. In one case the family history was positive for hyperlipidaemia. One case, where the repeat level was $5.32 \mathrm{mmol} / \mathrm{L}$ will most likely be controlled through dietary intervention. The other two cases were commenced on HMG CoA reductase inhibitors leading to significant reductions in serum cholesterol. The three percent incidence of hypercholesterolaemia, defined as total serum cholesterol greater than $5.2 \mathrm{mmol} / \mathrm{L}$, is remarkably different to the $20 \%$ incidence in professional skiers and $30.7 \%$ incidence previously found in professional cyclists. [4] The discrepancy may be explained by the differences in mean age of the subjects in the studies. It may be prudent that if screening 
is to be performed an assessment of serum cholesterol may be indicated in older athletes.

One case of haemochromatosis was revealed. This initially demonstrated increased serum iron and transferrin saturation (69\%) and a persistent elevation of transferrin saturation (57\%) on repeat testing. Serum ferritin was normal on each occasion (103.4 and $88.8 \mathrm{ng} / \mathrm{ml}$ ), respectively. The athlete was found to be homozygous for the C282Y mutation.

In terms of individual athletes, only $4 \%$ of biochemical screenings had a clinically significant effect. In terms of individual tests only 4 out of 2500 $(0.16 \%)$ were of clinical significance. These findings and the predominance of hypercholesterolaemia are remarkably similar to those of Ruttimann et al in their study of general practice patients.[9]

In general medicine, screening of healthy young persons for abnormalities of any of the parameters which are the subject of this study, including both serum cholesterol and blood glucose, is not currently recommended.[20] It may be, however, reasonable to screen those with a positive family history for early vascular disease, hyperlipidaemia or haemochromatosis.

General screening of elite athletes for a wide range of biochemical parameters is not justified on clinical grounds. It is likely to only reveal changes which are well documented as being consequent upon training or false positive readings which are close to the reference limits of the normal population and are related to the statistical methods used for definition of a "normal" population.

Such screening is further complicated in that true resting values are very difficult to assess in athletes who are training every day, if not twice a day, and important considerations such as normal biological[21] and diurnal variability[22], hydration, nutritional and fasting status are difficult to control.

In this study 82 athletes were recalled for repeat testing. This can engender significant concern in these athletes who may suspect that they have significant abnormality and also leads what now appears be to unnecessary discomfort and expense.

As the evidence for biochemical monitoring of training using parameters which are included in this study is sparse and in the absence of proven biochemical markers of overtraining it would appear that the only reasonable use for biochemical screening of elite athletes is in studies which seek to determine reference intervals for specific athletic populations. All other biochemical screening of athletes, with the exception of that for serum ferritin, the utility of which has been previously demonstrated, should be re-evaluated. 


\section{REFERENCES}

1. Mougios V. Reference intervals for serum creatine kinase in athletes. $\mathrm{Br} \mathrm{J}$ Sports Med 2007; Online 10.1136/bjsm.2006.034041

2. Fallon KE Screening for haematological and iron-related abnormalities in elite athletes - Analysis of 576 cases. J Sci Med Sport. 2007; In Press

3. Lippi G, Brocco G, Franchini M, Schena F, Guidi G. Comparison of serum creatinine, uric acid, albumin and glucose in male professional endurance athletes compared with healthy controls. Clin Chem Lab Med 2004; 42: 644647.

4. Lippi G, Schena F, Salvagno GL, Montagnana M, Ballestrieri F, Guidi GS. Comparison of the lipid profile and lipoprotein (a) between sedentary and highly trained subjects. Clin Chem Lab Med 2006; 44: 322-326.

5. Petibois C, Cazoria G, Deleris G. The biological and metabolic adaptations to 12 months training in elite rowers. Int J Sports Med 2003; 24: 36-42.

6. Hartmann U, Mester J. Training and overtraining markers in selected sport events. Med Sci Sports Exerc. 2000; 32: 209-215.

7. Tabas GH, Vanek MS. Is "routine" laboratory testing a thing of the past? Postgrad Med 1999; 105: 213-222.

8. Cebul RD, Beck JR. Biochemical profiles. Application in ambulatory screening and preadmission testing in adults. Ann Intern Med 1987; 106: 403413.

9. Ruttimann S, Dreifuss M, Clemencon D, di Gallo A, Dubach UC. Multiple biochemical blood testing as a case-finding tool in ambulatory medical patients. Am J Med 1993; 94; 141-148.

10. Nikolaidis MG, Protosygellou MD, Petridou A, Tsalis G, Tsigilis N, Mougios V. Hematologic and biochemical profile of juvenile and adult athletes of both sexes: implications for clinical evaluation. Int J Sports Med 2003; 24: 506-511.

11. Noakes TD. Effect of exercise on serum enzyme activities in humans. Sports Med 1987; 4: 245-267.

12. Remmers AR, Kaljot V. Serum transaminase levels. JAMA 1963; 185 : 148-150.

13. Skenderi KP, Kavouras SA, Anastasiou CA, Yiannakouris N, Matalas A-L. Exertional rhabdomyolysis during a $246-\mathrm{km}$ continuous running race. Med Sci Sports Exerc 2006; 38:1054-1057. 
14. Limdi JK, Hyde GM. Evaluation of abnormal liver function tests. Postgrad Med J. 2003; 79: 307-312.

15. Dickerson J, Bressler R, Christian CD. Liver function and low-dose estrogen oral contraceptives. Contraception. 1980; 22: 597-603.

16. Floreani A, Corsi N, Martines D, Varnier M, Naccarato R. No effect of endurance exercise on serum bilirubin in healthy athletes and with congenital hyperbilirubinaemia (Gilbert's syndrome). J Sports Med Phys Fitness. 1993; 33: 79-82.

17. Priest JB, Oei TO, Moorehead WR. Exercise -induced changes in common laboratory tests. Am J Clin Pathol 1982; 77: 285-289.

18. Clarkson PM, Kearns AK, Rouzier P, Rubin R, Thompson PD. Serum creatine kinase levels and renal function measures in exertional muscle damage. Med Sci Sports Exerc 2006; 38: 623-627.

19. Nagel D, Seiler D, Franz H. Biochemical, haematological and endocrinological parameters during repeated intense short term running in comparison to ultra-long-distance running. Int J Sports Med. 192; 13: 337343.

20. Royal Australian College of General Practitioners. Guidelines for preventive activities in general practice. $6^{\text {th }}$ Ed RACGP publications, 2005: 3943.

21. Bagger $M$, Petersen $\mathrm{PH}$, Pedersen PK. Biological variation in variables associated with exercise training. Int J Sports Med 2003; 24: 433-440.

22. Pocock SJ, Ashby D, Shaper AG, Walker M, Broughton PM. Diurnal variations in serum biochemical and haematological measurements. J Clin Pathol 1989; 42: 172-179.

"The Corresponding author has the right to grant on behalf of all authors and does grant on behalf of all authors, an exclusive licence (or non-exclusive licence for government employees) on a worldwide basis to the BMJ Publishing Group Ltd and it Licensees to permit this article to be published in British Journal of Sports Medicine editions and any other BMJPGL products to exploit all subsidiary rights, as set out in our licence http://bjsm.bmijournals.com/cgi/aletrs/etoc"

What is already known on this topic

There is currently no research data assessing the clinical utility of biochemical screening in elite athletes. 
What this study adds.

General screening of elite athletes for a wide range of biochemical parameters is not justified on clinical grounds.

It is likely to only reveal changes which are well documented as being consequent upon training or false positive readings which are close to the reference limits of the normal population and are related to the statistical methods used for definition of a "normal" population.

It may be, however, reasonable to screen those with a positive family history for early vascular disease, hyperlipidaemia or haemochromatosis. 